\title{
REFLECTION
}

\section{The Joy of Family Practice}

\section{William Ventres, MD, MA}

Master's Program in Public Health, University of El Salvador School of Medicine, San Salvador, El Salvador; and Department of Family Medicine, Oregon Health and Science University ${ }_{i}$ Portland, Oregon
Conflicts of interest: author reports none.

\section{CORRESPONDING AUTHOR}

William Ventres, MD, MA

Master's Program in Public Health

University of El Salvador School of

Medicine

Edificio "La Rotonda"

Calle Arce y Avenida 25 Sur

San Salvador, El Salvador

wventres@gmail.com

\begin{abstract}
Many family physicians have written about how they influence, nurture, and empower people in their communities of practice. In this essay, the author writes of the personal joys that family medicine has brought him. An expression of his appreciation for his work as a family doctor, it touches on 6 themes that continue to rejuvenate his practice: love, faith, mystery, place, dance, and medicine. By examining the emotional and psychological dimensions of these themes, he offers a path by which other family physicians may be able to find sustenance and joy in their daily work.
\end{abstract}

Ann Fam Med 2012;10:264-268. doi:10.1370/afm.1372.

Remember the book The Joy of Sex? I would like to write a book, The Joy of Family Practice. There is a tremendous amount of gratification and satisfaction that can come from this kind of medical practice. We as physicians bave the opportunity to develop the doctor-patient relationship to an incredible degree.

It's really an incredibly fulfilling undertaking, and it makes it worthwbile to get up in the middle of the night to go out and see somebody or to spend the time necessary and do whatever you can to belp people.

It gets back to the family -it's a way of becoming part of that person's family. That, to me, is more important than the salary, the benefits, and the prestige of being a doctor, and I think it's much more sustaining."

Lynn Carmichael ${ }^{1}$

\section{INTRODUCTION}

Two decades ago I had the privilege of interviewing Lynn Carmichael, one of the early leaders of the modern family medicine movement and the founder of the Society of Teachers of Family Medicine. I was new to practice, fresh out of a family medicine residency and a research fellowship. Lynn was one among many elder statesmen in the discipline. I didn't yet know what it meant to be a family physician-it took me quite some time in community practice to figure it out—and Lynn seemed so eloquent in his deep knowledge and understanding.

For years I hoped to read Lynn's book, the one to which he alluded to in our interview: "The Joy of Family Practice". But it never got written. Lynn had other responsibilities, I am sure, as chair of the Department of Family Medicine and Community Health at the University of Miami. Later he was afflicted with Alzheimer's disease and slowly, over years, lost his exuberance, his creativity, and his presence. All but a shadow of the Lynn I interviewed was gone. Then in 2009 he died. ${ }^{2}$

I have hoped, too, that in the absence of Lynn's ability to write of his joy in practice, someone else would write explicitly about the personal joy of being a family physician. To be sure, there are many who have touched on the subject. Our colleagues Lucy Candib, ${ }^{3}$ David Loxterkamp, ${ }^{4}$ John Frey, ${ }^{5}$ and many others in the United States have spoken to issues of relationship and community as family physicians. So have practitioners from other parts 
of the world, including Canada, ${ }^{6}$ the United Kingdom, ${ }^{7}$ the Iberian Peninsula ${ }_{1}^{8}$ and Latin America, ${ }_{1}^{910}$ where family medicine of one variant or another forms the foundation of their respective health care systems. Still, I have wanted to read of what the work of family medicine brings to us as professionals, as individuals, as people.

So rather than wait another 20 years, and with the understanding that I enter into the written expression of my joys as an exploration rather than as a pronouncement, here I write my "Joy of Family Practice". It is not a book-as a doctor in practice I have become accustomed to beginning and finishing tasks in short blocks of time. It is not a universal truth - what I write is born of my particular training and practice and my own signature responses. It is not complete-at 54 years of age I anticipate many years of practice ahead of me.

This "Joy of Family Practice", however, is my joy. It is a brief summary of why I keep coming back, day to day, month to month, year to year, and moment to moment, to do the work I do. It is a love story of sorts, an expression of my appreciation for the work I have chosen as a family physician-rich, engaging, and fulfilling-and, as such, it is with love I begin.

\section{LOVE}

Love is clearly a complex and easily misunderstood word, but I still enjoy using it to describe both what I bring to my practice and what I receive in return from my patients. Many years ago I read the Mexican poet and Nobel Laureate Octavio Paz's The Labyrinth of Solitude, in which he defined love as "a perpetual discovery, an immersion into the waters of reality, and an unending re-creation." ${ }^{111,12}$ I have yet to find a definition that works better for me as I put into words what I hope I offer to patients in examination rooms or hospital suites. To be sure, it has measures of mindfulness and presence and the Rogerian concept of unconditional positive regard ${ }_{1}^{13-15}$ but at its essence the love I speak of is filled with an awe of exploration that permeates my encounters with patients. Who is this person? Who is accompanying him or her? Why are they here? With what issues do they present, and what unsaid concerns lie behind their chief complaints? What are their struggles and where are their resiliencies?

That I am a family physician and not a psychiatrist means that the expression of this love is not solely bound by the world of words, but has physical elements as well. Auscultating heart sounds or palpating an abdomen with compassion, not lacking of sensitivity, does as much to create avenues of communication as does opening my ears to hear my patients' suffering and distress. That I am a family physician and not a subspecialist means that this expression is not bound by barriers of organ system, procedural domain, gender, or age, but is at once inclusive and expansive. It is a love expressed wherever the patient concern might be. That I am a family physician means, too, that this love is expressed with humility. In one sense, it is for the most part focused around everyday matters, both chronic concerns with which people walk the paths of their lives, and acute, generally short-term problems that occasionally show up on those paths as pebbles to be tripped over. In another sense, it is given in recognition that little things take on meanings much larger than they may seem. The welcoming attention I offer may be the single most important thing my patients receive that day-or that year.

In return, I am greeted with a reciprocal sense of love, a respect, a trust, and an invitation to join with my patients as they make their ways in life, with gratitude when things go well as well as when they do not. My patients know that I am not infallible-I do not represent myself as such and am ready to admit my limitations - but they know that I will be there for them as much as is possible in the context of their medical concerns. As a family physician, I am greeted with love born of the understanding that we are more alike than dissimilar, that we are more connected than alone, and that-professional role notwithstandingwe are on a common journey through illness and pain, through difficulty and infirmity as well as joy.

\section{FAITH}

Family medicine and family practice used to be considered 2 different sides of the same coin. Family medicine was the academic discipline, the research and teaching. Family practice was what one did in offices and hospitals, the daily work of attending to patients. For marketing and political reasons, more than anything else, "practice" was dropped and the work of family physicians was subsumed under family medicine. Yet I consider my work still a practice. It is a studied practice, one with knowledge and skills and scientific acumen. It is also a practice of faith.

The faith I refer to is not some dogmatic adherence to a set of beliefs or unquestioning surrender to someone else's authority, both of which seem to have created "turf" mentalities that divide people. It is a faith that by being open to patients as people in the context of medical encounters, something more therapeutic happens than is possible when strictly biomedical necessities are attended to. There exists a shared sense of possibility, a shared potential, and a shared understanding that leads us to go forward even when life is difficult or uncertain. It is a practiced faith in that, as a family physician, I must constantly be aware of looking 
for that potential, wherever it may exist in context of my patients' lives. It is a practiced faith, too, in that this abiding understanding helps support me in a work that is often challenging and occasionally baffling.

My work is a practice of faith because it draws on a worldview that is interdependent and inexplicable, much more complex than the reductionistic biomedical model that I was taught in medical school and residency. So many factors influence the health of my patients - diseases, behaviors, family dynamics, race, sex, geography, political climate, and money are but some of them. It is my job to sift through these with patients and, with intelligence, discernment, and heart, assist them in seeing the possibilities latent within change and help them move forward. Even when lives are not tidy and manageable or predictable - and they rarely are in the face of illness-I am there to observe, to recognize, to bear witness to, and to offer a path amidst the unknown.

\section{MYSTERY}

Among other reasons, family medicine is challenging because it deals with uncertainty, and I often think that it is my tolerance for uncertainty that sets me apart from my subspecialist colleagues. I deal with uncertainty, first, because my patients present with what are commonly poorly defined, undifferentiated problems, and these problems reflect a variety of possibly related or unrelated causal forces or events. Second, like most family physicians, I generally see patients in short blocks of time. Any sense of increasing certainty rarely comes to me instantaneously but rather over repeated visits with my patients. This sense is enhanced by an awareness of the communities in which my patients live, as well as by our understanding of how my patients live in those communities. Third, because I am a true generalist, there will always be an overabundance of information for me as a family physician to assimilate.

I was trained to look for and see information in objectified bits and pieces as a means to lessen doubtand I should add that this created within me an oppressive feeling of anxiety-but over time I have come to see uncertainty as something to be accepted as part of my work. It is not as though I have abandoned compulsiveness as a strategy to cope with uncertainty-physicians for the most part share this characteristic to some extent - but I have learned that uncertainty is less to be feared and avoided than to be creatively engaged as a mystery to be explored. ${ }^{16}$ It is as though I lean into the vague ambiguities that are inherent in the work I do, expecting there to be stories behind the pain and suffering my patients present with, knowing that I will not hear them all, believing that it is through time and trust and respect and insight_-appreciating my own abilities as a family physician to listen in context - that they will become evident, as is needed, as is important, and as is clinically relevant.

\section{PLACE}

The way I conceptualize my work as a family physician probably puts me on the periphery of allopathic medicine, where the hegemony of biomedical thinking reigns. Medical schools overwhelmingly teach their students from a Flexnerian foundation that prioritizes particularized knowledge at the expense of an integrated understanding of disease and health across the biopsychosocial spectrum. ${ }^{17,18}$ For the most part even family medicine residencies train their residents in such manners and settings that suggest that family practice is but the compilation of sets of knowledge, mostly modeled after subspecialty practice and mostly taught in hospitals or their associated clinics. Ironically, it has been some community-based subspecialists who have best understood my work. I suspect that while they recognize my limitations of knowledge among the patients I refer to them for consultation, they also recognize their own limitations in understanding the complexities of patient care outside the boundaries of conventional medicine-where my expertise lies.

At one and the same time, I find satisfaction knowing that my work positions me at the core of why so many people entered medicine: to bring care to people; to offer hope when possible and solace when needed; to cure when it is a reasonable goal, to manage and support when it is not. From an organizational perspective, family medicine is an eminently logical foundational layer within a rational health care system, and I am extremely proud to be a very small part of that foundation. But we do not have a rational system of care here in the United States, ${ }^{19}$ and it is difficult and often lonely to avoid the strong pulls that money and status and ideology present in our country. As for me, I take refuge in accepting that there are more important things in life than those that can be conferred by the traditional accoutrements of our culture. I also know the central role I play in my patients' lives, as a counselor, as a guide, and as their personal physician.

\section{DANCE}

It is in my role as personal physician that I sometimes find myself figuratively dancing at work. My fashion sense is not flashy, my moves are not fancy, and I have been known to miss beats and step on toes occasionally. But there is an undeniable elegance to what I am doing, to how I am interacting, and to the knowledge and skills and attitude that I bring to my encounters with patients. 
I find myself dancing with patients when there is a give and take between us, giving space for each one of us to lead and follow when it is most appropriate. When I lead, my intent is to help my patients and their families to feel a sense of competency in the face of challenge. When I follow, it is to allow them room to express their fears as well as their own special strengths. I find myself dancing with my patients when the rhythm of their needs and my responses create some mutually resonant rapport. I find myself dancing with them when, after the 10 or 15 or 25 minutes of our visit is done and the tasks of problem list review and medication reconciliation and charting are completed and I am leaving the examination room, I can honestly say, "I'll be thinking about you. Until our next visit."

When we are dancing, there is a flow between my patients and me that suggests connections beyond the examination room, residual reverberations of words and movements and intents. There is a temporal connection that extends well after the office visit is over, one that I believe helps direct their welfare at the same time it nurtures my well-being. There is a human connection, too, one that extends to and is amplified by the people around us, the receptionists and nurses and laboratory technicians and social workers with whom I work. As well, there is a spatial connection that helps all our lives become more expansive, more readily willing to grow, and more conscious of kindness to self and others in the face of adversity. The art of the dance is ultimately, about dignity and grace across dimensions of time and person and place, about sharing a generosity of spirit when the despair of illness threatens, and allowing the effects of that generosity to linger well after my patients and I part.

\section{MEDICINE}

The foundation of what I do as a family physician is address the medical concerns as my patients present them. I hear their stories of illness, how they understand their perceived problems. I conduct a physical examination. I recollect bits and pieces and, sometimes, entire wholes of information I have learned, of facts and theories and patterns, and reconstruct them in my own mind focusing on the specific and particular needs of the person or people before me. I diagnose. I treat. I do what physicians of whatever ilk do: I attend to my patients' needs as best I can.

In response to those needs, I play many roles: interpreter, guide, diagnostician, advocate, and healer. In playing any one of these roles, I am supported by the structure, the knowledge, and the language I learned many years ago in medical school and residency. I am supported as well as by the titles I have earned, first as physician and later as family physician. But while my medical training continues to provide a framework for my work, it has been but a start to something more whole, more complete, and more authentic — to that which I truly treasure-my work as I see it, as a family doctor.

\section{CONCLUSION}

I am not oblivious to, nor have I been immune to, the difficulties that family physicians (or other primary care clinicians) face in today's medical environment. I certainly know that there are days when my family practice is not so joyful, when things go wrong, when mistakes are made, and when people (patients and professionals alike) are difficult to reach or even refuse to join in. I am aware, too, that within family medicine there are those who will not be able to comprehend my insights into practice and may, perhaps, even be threatened by them. But in writing this, I have chosen to hold up for inspection the fulfillment that my work brings to me. Rather than focus on the challenges of my work as a family doctor, some due to a socioeconomic structure that has fostered the creation of a medical industrial complex and others to the human need for conservatism and conformity, ${ }_{1}^{20,21}$ I have chosen here to explore and appreciate the sources of that happiness and what continues to nurture it.

For it is in this exploration and appreciation that I am best able to find the gratification and satisfaction that Lynn Carmichael shared with me many years ago It is by examining the myriad facets of my daily work, modest as they are meaningful, that I am able to sustain myself in contentment as a family physician. It is in doing this that I open myself-and my patients-to joy. So may we all.

To read or post commentaries in response to this article, see it online at http://www.annfammed.org/content/10/3/264.

Key words: attitude of health personnel; clinical medicine; ethics, medical; family practice; humans; interprofessional relations; medical education, graduate; medical education, undergraduate; philosophy, medical; physician-patient relations; physician's practice patterns; physician's role; practice; professional practice.

Submitted June 29, 2011; submitted, revised, August 23, 2011; accepted October 10, 2011

Funding support: Dr Ventres was a Fulbright Scholar and received financial support from the Fulbright Commission of the United States Department of State.

Disclaimer: Neither the Fulbright Commission nor the US Department of State had any role in the preparation, review, or approval of the manuscript. The views expressed in this article are those of the author and do not reflect those of the US Department of State, the Institute of International Education, or the Fulbright Program. 
Acknowledgments: Several people contributed to this essay through their thoughtful comments, critical support, and astute editing. I am indebted to John Frey, Betsy Garrett, and Jeannette South-Paul; to my colleagues at the Oregon Health and Science University, John Muench and Emmy Davison; and to Richard Stevenson. I appreciate as well Lynn Carmichael's children for their permission to share my remembrances of their father.

\section{References}

1. Carmichael L. Voices from family medicine: Lynn Carmichael. Interview by William B. Ventres and John J. Frey. Fam Med. 1992;24(1): 53-57.

2. Frey JJ. "Who is going to take care of the people?" Lynn Carmichael and his times. Fam Med. 2009;41(8):552-554.

3. Candib LM. Medicine and the Family. New York, NY: Basic Books; 1995.

4. Loxterkamp D. A vow of connectedness: views from the road to Beaver's farm. Fam Med. 2001;33(4):244-247.

5. Frey JJ III. Building our sense of place. Fam Med. 1998;30(6):401-403.

6. McWhinney I, Freeman T. A Textbook of Family Medicine. 3rd ed. New York, NY: Oxford University Press; 2009.

7. Berger J. A Fortunate Man. New York, NY: Vintage; 1997.

8. Turabian JL. Perez Franco B. El efecto de ver por primera vez el mar. Un intento de definición de la Ley Generalde la medicina de familia: La entrevista es la clínica [The effect of seeing the sea for the first time. An attempt at defining the family medicine law: the interview is clinical medicine]. Aten Primaria. 2008;40(11):565-566.

9. Blasco PG, Levites MR, Janaudis MA, et al. Family medicine education in Brazil: challenges, opportunities, and innovations. Acad Med. 2008;83(7):684-690.
10. Presno Labrador C. El médico de familia en Cuba [The family physician in Cuba]. Rev Cubana Med Gen Integr. 2006;22(1). http://scielo.sld.cu/scielo.php?script=sci_arttextEpid=S086421252006000100015 \&lng=en. Accessed May 23, 2011.

11. Paz O, Kemp L. translator. The Labyrinth of Solitude: Life and Thought in Mexico. New York, NY: Grove Press; 1961:42.

12. Ventres WB. Cultural encounters and family medicine: six lessons from South America. J Am Board Fam Pract. 1997;10(3):232-236.

13. Epstein RM. Mindful practice. JAMA. 1999;282(9):833-839.

14. McPhee SJ. The practice of presence. Presented at: Alpha Omega Alpha Honor Society Spring Lecture; April 17, 1981; Piscataway, NJ.

15. Rogers C. On Becoming a Person. Boston, MA: Houghton Mifflin Company; 1961.

16. Gabbard GO. The role of compulsiveness in the normal physician. JAMA. 1985;254(20):2926-2929.

17. Brody H, Sparks HV Jr, Abbett WS, Wood DL, Wadland WC, Smith RC. The mammalian medical center for the 21st century. JAMA. 1993;270(9):1097-1100.

18. Engel GL. How much longer must medicine's science be bound by a seventeenth century world view? In: White KL. The Task of Medicine: Dialogue at Wickenburg. Menlo Park, CA: The Henry J. Kaiser Family Foundation; 1988:113-136.

19. Ferrer RL. A piece of my mind: within the system of no-system. JAMA. 2001;286(20):2513-2514.

20. Starr P. The Social Transformation of American Medicine. New York, NY: Basic Books; 1982.

21. Coulehan J, Williams PC. Conflicting professional values in medical education. Camb Q Healthc Ethics. 2003;12(1):7-20.

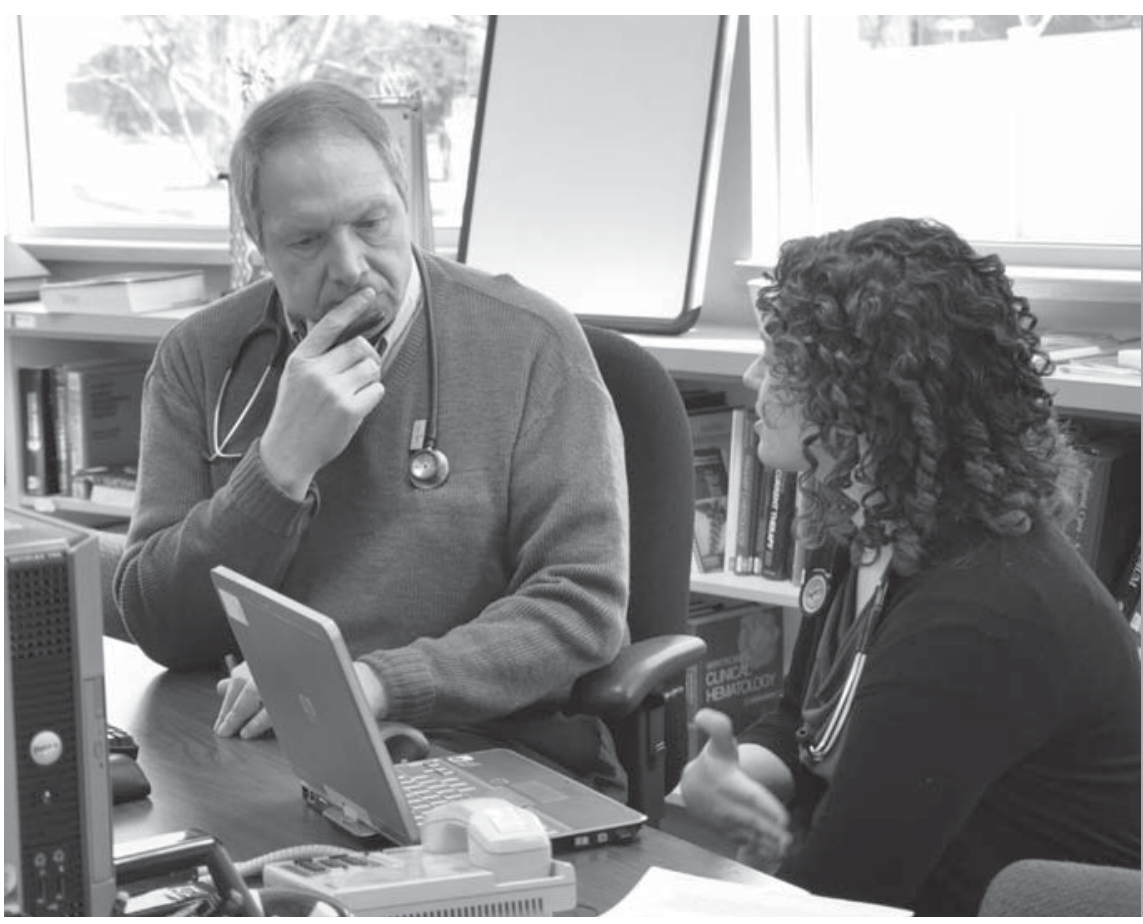

Just released...

CLERKSHIP CURRICULUM RESOURCE FOR STFM MEMBERS

Define and develop a more effective third-year clerkship with a new online resource based on the National Family Medicine Clerkship Curriculum.

- Core content and competencies

- Learning objectives

- Assessment tools

- Educational strategies

- Role definitions 